\title{
Correction to: Consumer protection and risk assessment: sensitising substances in consumer products
}

\author{
Hermann-Josef Thierse · Andreas Luch
}

Published online: 15 November 2019

(C) The Author(s) 2019

\section{Correction to:}

\section{Allergo J Int 2019 28:167-182}

https://doi.org/10.1007/s40629-019-0093-3

The article "Consumer protection and risk assessment: sensitising substances in consumer products", written by Hermann-Josef Thierse and Andreas Luch, was originally published Online First without Open Access. After publication in volume 28, issue 6, page 167-182 the author decided to opt for Open Choice and to make the article an Open Access publication. Therefore, the copyright of the article has been changed to (C) The Author(s) 2019 and the article is forthwith distributed under the terms of the Creative Commons Attribution 4.0 International License (http://creativecommons.org/licenses/by/4. $0 /$ ), which permits use, duplication, adaptation, distribution and reproduction in any medium or format, as long as you give appropriate credit to the original author(s) and the source, provide a link to the Creative Commons license, and indicate if changes were made.

The original article has been corrected.
The online version of the original article can be found under https://doi.org/10.1007/s40629-019-0093-3.

PD Dr. H.-J. Thierse · Prof. Dr. Dr. A. Luch $(\varangle)$ Department of Chemical and Product Safety, Federal Institute for Risk Assessment, Max-Dohrn-Straße 8-10, 10589 Berlin, Germany

andreas.luch@bfr.bund.de

PD Dr. H.-J. Thierse

hermann-josef-thierse@bfr.bund.de 